\title{
Secondary Radiation in lon Therapy and Theranostics: A Review
}

\author{
Maitreyee Nandy* \\ Saha Institute of Nuclear Physics, Kolkata, India
}

Ion therapy has emerged as one of the preferred treatment procedures in some selective indication of cancer. The actual dose delivered to the target volume may differ from the planned dose due to wrong positioning of the patient and organ movement during beam delivery. On the other hand, some healthy tissues outside the planned volume may be exposed to radiation dose. It is necessary to determine the primary particle range and the actual exposed volume during irradiation. Many proposed techniques use secondary radiation for the purpose. The secondary radiation consists mainly of neutrons, charged fragments, annihilation photons, among others, and prompt gammas. These are produced through nuclear interaction of the primary beam with the beam line and the

OPEN ACCESS

Edited by:

Marco Durante,

GSI Helmholtz Center for Heavy lon Research, Germany

Reviewed by:

Alessio Sarti,

Sapienza University of Rome, Italy

Satoshi Kodaira,

National Institutes for Quantum and Radiological Science and Technology, Japan

Ilaria Mattei,

INFN-Sezione di Milano, Italy

${ }^{*}$ Correspondence:

Maitreyee Nandy

maitreyee.nandy@saha.ac.in

Specialty section: This article was submitted to Medical Physics and Imaging, a section of the journal

Frontiers in Physics.

Received: 24 August 2020 Accepted: 31 December 2020 Published: 25 February 2021

Citation:

Nandy M (2021) Secondary Radiation in Ion Therapy and Theranostics:

A Review.

Front. Phys. 8:598257. doi: 10.3389/fphy.2020.598257 patient's body tissue. Besides its usefulness in characterizing the primary beam, the secondary radiation contributes to the risk of exposure of different tissues. Secondary radiation has significant contribution in theranostics, a comparatively new branch of medicine, which combines diagnosis and therapy. Many authors have made detailed study of the dose delivered to the patient by the secondary radiation and its effects. They have also studied the correlation of secondary charged particles with the beam range and the delivered dose. While these studies have been carried out in great detail in the case of proton and carbon therapy, there are fewer analyses for theranostics. In the present review, a brief account of the studies carried out so far on secondary radiation in ion therapy, its effect, and the role of nuclear reactions is given.

Keywords: theranostics, neutrons, prompt gamma, charged particle, ion therapy, secondary radiation

\section{INTRODUCTION}

In the growing incidence of malignant diseases, ion therapy has emerged as a preferred choice of treatment in the case of some selective indications [1-4]. During the passage of charged particles through the patient's body, electronic interactions contribute to the major part of energy deposition, while nuclear reactions lead to the production of neutrons, gamma rays, and secondary charged particles (SCPs). The energy deposition characteristics and the depth dose profile of the charged particle beams help to have high-dose conformity in the target volume in a static patient in an ideal situation. But variation in patient positioning and organ movement during treatment cause a fraction of the dose to be delivered outside the planned target volume $[5,6]$. The problem can be circumvented if the actual volume of dose distribution can be dynamically imaged. This is achieved to some extent in image-guided radiotherapy (IGRT) [7] whence the target volume is imaged during treatment. Proposed techniques also use the SCPs to determine the primary particle range and the delivered dose during patient irradiation. Theranostics is an improved version of therapy [8] which combines treatment with simultaneous imaging of the region of interest. This is gradually emerging as a targeted and efficient mode of treatment. 
Secondary particle dose is clinically important because neutrons can result in radiation dose to a distant organ, while heavy fragments can locally deposit a high dose. Both neutrons and SCPs have high radiobiological effectiveness (RBE). So measurement of yield, flux, and dose of the secondary particles is crucial for assessing the probability of radiogenic cancer [9] at a later stage. As the prospect of new beams is being studied, benefits as well as risks from secondary radiation need to be investigated thoroughly.

This is a review work of the studies carried out by different authors on secondary radiation in ion therapy and in theranostics, its effect, and the role of nuclear reaction. Yield and dose distribution of charged particles and neutrons from ioninduced reaction in tissue, their correlation with the primary ion range, and contribution to the total dose will be discussed.

\section{SECONDARY RADIATION IN ION BEAM THERAPY}

In radiotherapy, exposure to the healthy tissues is lesser in the case of charged particle therapy (CPT) compared to that in the case of photon therapy due to the characteristic of interaction and energy deposition of charged particles in matter. In charged particle therapy, the energy of the carbon beam is in the range of $\sim 80-430 \mathrm{MeV} / \mathrm{u}$, while the proton energy is in a lower range. For these moderately relativistic particles, the energy loss takes place through Coulomb and nuclear interaction. Nuclear interaction results in the loss of beam intensity contributing to both longitudinal and lateral dose profile $[10,11]$. Multiple elastic scattering on the target nuclei contributes to the lateral profile and results in a broadening of the beam. Inelastic scattering with the atomic electrons contributes to the longitudinal profile. In CPT, nuclear reaction of the primary beam takes place both with the beam line components and within the patient's body. This leads to the production of neutrons, protons, heavier nuclear fragments, and deexcitation gamma rays. The nuclear fragments may consist of positron emitters and other radioactive isotopes. The former will give rise to annihilation gamma rays. Annihilation gammas, prompt gamma rays, neutrons, and the SCPs may help in dynamic imaging of the dose distribution. In proton therapy, nuclear fragmentation results in target fragments which consist mainly of secondary protons and neutrons. In heavy ion therapy, both target and projectile fragments are produced. Both the projectile and the target fragments contribute to the increase in the RBE. The projectile fragments enhance the lateral spread of the beam and add to the dose in the tail region of the Bragg peak. The dose distribution due to SCPs, neutrons, and gammas needs to be determined accurately to assess the biological effect.

Proton and carbon beams are most widely investigated for ion beam therapy. New beams like ${ }^{4} \mathrm{He},{ }^{16} \mathrm{O}$ are being studied to assess their possible advantages in ion beam therapy. ${ }^{4} \mathrm{He}$ ions might turn out to be a good choice, as projectile fragmentation and neutron production are expected to be lower than in the case of ${ }^{12} \mathrm{C}$ beams while having good localization of the energy deposition [12, 13]. For ${ }^{16} \mathrm{O}$, fragmentation is higher and in vitro studies had also provided a slightly larger RBE value $[14,15]$ compared to ${ }^{12} \mathrm{C}$, but carbon beam has a higher impact on cell survival. However, in all the cases, actual volume which is exposed to primary and secondary radiation strongly depends on patient positioning and on anatomical variation of the target organ during treatment $[5,6]$. This necessitates determination of the actual volume where the dose is released. The SCPs produced in the nuclear reaction, particularly the secondary protons, can be well used as a tool for imaging in CPT $[16,17]$.

\section{Secondary Charged Particles Experimental Studies}

Cross-section, total yield, fluence distribution of SCPs, and their contribution to the total dose had been investigated by several authors [12-39]. Target fragmentation for proton induced reactions in tissue equivalent targets like water, PMMA, C, and $\mathrm{CH}_{2}$ was studied in the energy range of $40-250 \mathrm{MeV}$ [19-21]. A study on $250 \mathrm{MeV}$ proton on water showed that around $40 \%$ of the primary particles were lost in inelastic collision on their way up to the Bragg peak. The LET value and the range of the target fragments produced in these interactions were between $983 \mathrm{keV} / \mu \mathrm{m}$ down to $14 \mathrm{keV} / \mu \mathrm{m}$ and $2.3-68.9 \mu \mathrm{m}$, respectively. This resulted in the alteration of the fixed RBE of 1.1 used for proton therapy beam and contributed to the dose beyond the planned target volume [21]. For an unmodulated $160 \mathrm{MeV}$ proton beam and a target volume of $3 \times 3 \times 3 \mathrm{~cm}^{3}$, the dose from secondary protons to the proximal part of the Bragg peak was $\sim 10 \%$ [19]. The dose contribution from $d, t, \alpha$, and ${ }^{3} \mathrm{He}$ was less than $0.1 \%$ of the total dose proximal to the Bragg peak.

Nuclear fragmentation in carbon-induced reaction in tissue equivalent targets at $80-430 \mathrm{MeV} / \mathrm{u}$ was measured in many works [22-39] to determine the actual dose and range. The total [22-26] and partial $(\Delta \mathrm{Z}=1,2,3$ for the formation of $\mathrm{B}, \mathrm{Be}$, and $\mathrm{Li}$, respectively) $[22,23]$ charge-changing cross-sections in the interaction of ${ }^{12} \mathrm{C}$ in water were determined between 110 and $600 \mathrm{MeV} / \mathrm{u}$. The total SCP production cross-section was found to decrease as the beam energy increased in the work of Golovchenko et al. [22], while no such trend was observed in [23]. Production of B was measured to be $\sim 2.3-3$ times that for $\mathrm{Be}$ $[22,23]$. Charge-changing cross-sections for ${ }^{16} \mathrm{O}$ beam incident on thick targets of water and carbon were also measured [24].

Kinetic energy of the secondary protons emitted in the interaction of therapeutic ${ }^{12} \mathrm{C}$ beams extended beyond the primary beam energy per nucleon [27, 28]. At $80 \mathrm{MeV} / \mathrm{u}$ beam energy, yield of protons with $\mathrm{E}_{\mathrm{p}}=83 \mathrm{MeV}$ was found to be $\sim 2.7 \times 10^{-4} \mathrm{sr}^{-1}$ [27]. At $200 \mathrm{MeV} / \mathrm{u}$, energy of emitted protons extended beyond twice the beam energy per nucleon [28] and the yield of protons with $\mathrm{E}_{\mathrm{p}}=350 \mathrm{MeV}$ was $\sim 5 \times$ $10^{-5}$ ion $^{-1} \mathrm{sr}^{-1} \mathrm{MeV}^{-1}$.

Production of secondary fragments for carbon-induced reactions at $95 \mathrm{MeV} / \mathrm{u}[25,29]$ and for $200-400 \mathrm{MeV} / \mathrm{u}$ was measured and discussed in several works [28, 30-39]. Among all the fragments, yield of $\mathrm{H}$ and $\mathrm{He}$ was highest [28, 30, 31] and was similar or higher than the primary ions near the end of range. The yield fell off rapidly as the fragment charge increased [28]. Beyond the Bragg peak, light fragments $\mathrm{H}, \mathrm{He}, \mathrm{Li}, \mathrm{Be}$, and $\mathrm{B}$ had significant contribution. At $400 \mathrm{MeV} / \mathrm{u}$ beam energy, the 
fragments penetrated few centimeters after the Bragg peak [30, 33]. These fragments would thus contribute to the delocalization of dose.

The angular distribution of the fragments was forward peaked for all fragments, was broad for light fragments, and became narrower as nuclear charge increased [30, 33]. At 219 and $280 \mathrm{MeV} / \mathrm{u}$ beam energy, protons had a broad angular range (up to $10^{\circ}$ ), but the primaries were confined within a narrow cone [34]. At $200 \mathrm{MeV} / \mathrm{u}$, fragments heavier than He were confined in a cone of about $5^{\circ}$ width. This suggested that the angular distribution was governed by the fragmentation process and not affected much by Coulomb scattering. The yield of secondary fragments integrated between 0 and $10^{\circ}$ was highest for protons and lowest for Be [28]. At $400 \mathrm{MeV} / \mathrm{u}$ beam energy, the FWHM for $\mathrm{H}, \mathrm{He}$, and $\mathrm{B}$ was $10,5.3$, and $3^{\circ}$, respectively [30]. Higher FWHM was measured in the works of G. D. Lellis et al. [32] and K. Gunzert-Marx et al. [28].

The contribution of the secondary fragments to the dose equivalent within the Bragg peak was $20 \%, 13 \%$, and less than $\sim 8 \%$ of the total dose for $157 \mathrm{MeV}$ proton, $145 \mathrm{MeV} / \mathrm{u}$ ${ }^{4} \mathrm{He}$, and $219-383 \mathrm{MeV} / \mathrm{u} 12 \mathrm{C}$ beams, respectively [12, 13, 34]. Beyond the Bragg peak, the total dose was contributed by the secondary fragments only. This dose in the tail region might affect the healthy tissue [30, 33].

At therapeutic energies, the target fragmentation rate was 3.62 times higher for carbon ion compared to that for proton beam [12]. But the absorbed dose and dose equivalent due to the secondary target fragments (STFs) were $0.22 \%$ and $4 \%$, respectively, of the primary ion dose for ${ }^{12} \mathrm{C}$, compared to $1.2 \%$ and $20 \%$, respectively, for proton beam. This was explained from the fact that though the yield of STFs increased with $Z / \beta$ ( $\beta=$ velocity of primary ion), the number of primary ions required to produce a given dose decreased as $Z^{2}$ [40]. These results excluded the dose contribution due to secondary neutrons produced in the reaction. Among the secondary fragments, the highest dose was contributed by the light fragments $\mathrm{H}$ and $\mathrm{He}[30,31]$ in the tail region behind the Bragg peak. They caused delocalization of the dose, followed by Li.

Besides proton and carbon, performance of ions like ${ }^{4} \mathrm{He},{ }^{16} \mathrm{O}$, and ${ }^{20} \mathrm{Ne}$ in heavy ion therapy was investigated in several works $[14,15,41-49]$. The total number of secondary protons produced by $220 \mathrm{MeV}{ }^{12} \mathrm{C}$ beam in PMMA target at $90^{\circ}$ was $(4.49 \pm$ $0.13 \pm 0.59) \times 10^{-3} \mathrm{sr}^{-1}$ which was $\sim 4.5$ times that produced by $125 \mathrm{MeV}{ }^{4} \mathrm{He}$ (having the same range as $220 \mathrm{MeV}{ }^{12} \mathrm{C}$ in PMMA) [41, 42]. Production of ${ }^{2} \mathrm{H}$ and ${ }^{3} \mathrm{H}$ was $\sim 5 \%-10 \%$ and $\sim 1 \%-2 \%$, respectively, of the total production of ${ }^{1} \mathrm{H}+{ }^{2} \mathrm{H}+{ }^{3} \mathrm{H}$. For $125 \mathrm{MeV} / \mathrm{u}{ }^{4} \mathrm{He}$ projectile, the energy of the emitted ${ }^{1} \mathrm{H}$ extended beyond $240 \mathrm{MeV}$ at $5^{\circ}$ [42]. Significant production of $\beta^{+}$was also reported for ${ }^{4} \mathrm{He}$ ion on PMMA target [43]. Secondary proton fluence from $300 \mathrm{MeV} / \mathrm{u}{ }^{16} \mathrm{O}$ induced reaction on PMMA target was measured to be $(74.18 \pm 0.40 \pm 13.02) \times 10^{-3} \mathrm{sr}^{-1}$ at $60^{\circ}$ and was $~ 6.5$ times lower at $90^{\circ}$ [14]. At $210 \mathrm{MeV} / \mathrm{u}{ }^{16} \mathrm{O}$ beam energy, these values were $\sim 3.3-3.6$ times lower. For the interaction of $670 \mathrm{MeV} / \mathrm{u} \mathrm{Ne}$ beam in water, oxygen, and fluorine had the highest yield among the target fragments with $\mathrm{Z} \geq 3$, while at
$400 \mathrm{MeV} / \mathrm{u}$ in PMMA target, oxygen had the highest yield followed by carbon and nitrogen [31]. Boron was found to have significant contribution at both the energies [31, 46]. In studying the efficacy of intensity modulated composite particle therapy (IMPACT), influence of the secondary particles on LET distribution was assessed [47, 48].

In $\mathrm{CPT}$, annihilation gammas from positron emitters produced in nuclear fragmentation can be used for imaging during therapy. In measuring the mean range of different stable beams in water, polyethylene, and PMMA, from activity distribution using annihilation gammas, highest amount of information was obtained in the case of ${ }^{16} \mathrm{O}$ beam to determine the mean range of the beam accurately. Thus, ${ }^{16} \mathrm{O}$ turned out to be the optimum among stable beams for monitoring the range from annihilation gammas [50]. In proton therapy, annihilation gammas could be used to achieve a dose-volume guided radiotherapy system with a $2 \mathrm{~mm}$ spatial resolution [51, 52]. The profile of the prompt gamma rays produced in the interaction of the ion beam was also used to establish a relation between the gamma ray profile and the primary ion range [53-58]. Time-of-flight (TOF) technique was used to discriminate between prompt gammas, neutrons, and neutron-induced gamma rays. With less background and higher contrast, the peak and the dose fall off position could be measured with millimetric precision for proton beams [58].

The tracks of SCPs, their flux, velocity, and spatial distribution were analyzed and reviewed for monitoring in hadron therapy $[16,17,19,59,60]$. The Bragg peak position could be determined from the emission profile of the SCPs with high accuracy. A linear correlation was observed between the position of the distal edge of the secondary particle tracks and the Bragg peak position [19]. Accuracy of the method depended on several factors like multiple scattering of the SCPs, inherent fluctuation in the number of emitted charged particles, and overall statistics of the measured data. Feasibility study of range monitoring of carbon ions with secondary protons was carried out using interaction vertex imaging $[17,59]$ which showed that single proton detection in coincidence with the incoming beam was more promising.

\section{Simulation Studies}

Simulation studies of ${ }^{12} \mathrm{C}$ interaction in water, with the Monte Carlo Geometry and Tracking 4 (GEANT4) [61] code, showed that, at a beam energy of $155 \mathrm{MeV} / \mathrm{u}$, more than $6 \%$ of the total dose was deposited by the SCPs and gamma rays from the phantom surface to $90 \%$ of the distal edge of the Bragg peak [62]. At beam energies of 262 and $369 \mathrm{MeV} / \mathrm{u}$, these contributions were, respectively, $\sim 14 \%$ and $23 \%$. As the primary dose sharply fell off beyond the Bragg peak, the secondary radiation played a much more important role. From $90 \%$ of the distal edge to $5 \mathrm{~cm}$ after the Bragg peak, the SCPs along with the gamma radiation contributed $\sim 71 \%, 82 \%$, and $87 \%$ to the total dose, at beam energies of 155,262 , and $369 \mathrm{MeV} / \mathrm{u}$, respectively [62]. The major contributor to the secondary dose was ${ }^{11} \mathrm{~B}$ along with $\mathrm{H}$ and $\mathrm{He}$ near and beyond the Bragg peak [63]. At $290 \mathrm{MeV} / \mathrm{u}$, contribution from $\mathrm{H}$ and $\mathrm{He}$ ions extended more than $160 \mathrm{~mm}$ beyond the Bragg peak. This could affect healthy tissues outside the target volume. In the initial part of the 
primary beam path, LET of the primary ${ }^{12} \mathrm{C}$ beam was $\sim 33.6 \mathrm{keV} /$ $\mu \mathrm{m}$ while those for ${ }^{14} \mathrm{~N},{ }^{15} \mathrm{~N}$, and ${ }^{16} \mathrm{O}$ were almost 30 times more. However, this pattern drastically changed near and beyond the distal end of the Bragg peak. Here, ${ }^{11,12} \mathrm{C},{ }^{16} \mathrm{O}$, and ${ }^{13,14,15} \mathrm{~N}$ had almost comparable LET [62]. Experimentally measured LET distribution of SCPs, for $380 \mathrm{MeV} / \mathrm{u}{ }^{12} \mathrm{C}$ beam, was compared with the GEANT simulation $[64,65]$. The measured values were well reproduced by the simulation [65]. In a benchmark analysis of the reaction models available in GEANT4 simulation kit for fragmentation studies $[66,67]$, it was observed that the measured fragment yields were reproduced by the models within $5-35 \%$. The QMD model with Frag option gave the best agreement. The kinetic energy and the angular distributions were best reproduced by the QMD and INCL++ models, respectively [67]. GEANT4 simulation was used to compare the mixed radiation field produced by $162,290 \mathrm{MeV} / \mathrm{u}{ }^{12} \mathrm{C}$ beam and $192,245 \mathrm{MeV} / \mathrm{u}$ ${ }^{16} \mathrm{O}$ beam in water [68]. At these energies, the ranges of the $\mathrm{C}$ and $\mathrm{O}$ beams were the same in the target. Production of nuclear fragments was higher for ${ }^{16} \mathrm{O}$ compared to that for ${ }^{12} \mathrm{C}$. As a result, energy deposition beyond the Bragg peak and out of the field would be more for ${ }^{16} \mathrm{O}$.

The PHITS code [69] was used to investigate the role of nuclear fragmentation and secondary radiation in carbon therapy [70, 71]. In the PHITS simulation, the Bragg curve peaked at a depth slightly lower than that given by the measured data. This was attributed to PHITS underestimating the probability of fragment production [70]. Using the Monte Carlo particle transport code FLUKA [72], the energy distribution, range distribution, and fragment fluence were studied for $\mathrm{H}, \mathrm{He}, \mathrm{Li}, \mathrm{B}, \mathrm{Be}, \mathrm{C}, \mathrm{N}$, and $\mathrm{O}$ in proton-induced reaction on water between 40 and $200 \mathrm{MeV}$ [73]. The energy distribution was highly asymmetric. For Li and heavier fragments, the energy distribution extended only well below $20 \mathrm{MeV}$. Proton energy spectrum had a broad shoulder and extended above $20 \mathrm{MeV}$.

Dedes and Parodi had reviewed the status of Monte Carlo simulation of particle interaction in tissue in carbon ion therapy [74].

\section{Neutrons}

Experimental and simulation studies were carried out by several authors [28, 75-91] to investigate the fluence and dose of secondary neutrons in proton and carbon ion therapy. Production of secondary neutrons and their dose profile were found to strongly depend on the irradiation facility [75-79]. Epidemiological studies were also undertaken to analyze the significance of the neutron dose in proton therapy [92].

The incident beam energy in ion therapy is high but gradually decreases in tissue. For carbon beam from therapeutic energy down to $\sim 12 \mathrm{MeV} / \mathrm{u}$, the reaction cross-section is highest at the latter point [80]. At these energies, the neutron field consists of both thermal and high-energy neutrons. Thermal neutrons have isotropic distribution while the fast neutrons produced have a strong energy dependence and forward peaked angular distribution. Neutrons with energy above $20 \mathrm{MeV}$ were observed only close to the beam axis [81]. The high-energy neutrons, above $20 \mathrm{MeV}$, could contribute as high as $53 \%$ of the total dose at the position of highest neutron dose. The scattered neutron distribution was highly complex and depended on the spatial characteristics of the treatment facility. This necessitated a detailed Monte Carlo simulation of the secondary neutron field [82].

In proton radiotherapy at $\sim 172 \mathrm{MeV}$, the largest neutron dose was obtained at a distance of $115 \mathrm{~cm}$ from the isocenter. The finding conformed to the fact that neutrons could significantly contribute to the dose outside the target volume [83].

From a comparison of the secondary neutron ambient dose equivalent $\left(\mathrm{H}_{\mathrm{n}}^{*}(10)\right)$ in passive particle radiotherapy, it was confirmed that, for passively scanned beams, $\mathrm{H}_{\mathrm{n}}^{*}(10)$ was less in carbon therapy than in proton therapy [84]. This dose depended on the operational beam setting but not on the method for making a laterally uniform field. $\mathrm{H}_{\mathrm{n}}^{*}$ (10) for active scanned beam was similar for carbon and proton beams. For an active scanned carbon beam, this dose was at the most $15 \%$ of passive beam [85]. The observation could be attributed to the fact that the contribution to the total neutron dose from external neutrons was much reduced by an active scanned beam compared to a passive one. For a $250 \mathrm{MeV}$ passively scanned proton beam, $\sim 35 \%$ of the total neutron dose was due to neutrons with $E_{n} \geq 20 \mathrm{MeV}$ [86]. The neutron dose in passive particle radiotherapy was either similar to or less than that in photon therapy [84]. Comparison of the neutron yield in CPT and in high-energy photon therapy showed that, at therapeutic energies, the yield of most effective neutrons $\left(\sim 1 \mathrm{MeV}\right.$ with $\mathrm{w}_{\mathrm{R}}$ of 20$)$ was much lower in ion therapy [87]. This was one of the main advantages of ion therapy over photon therapy.

A FLUKA Monte Carlo simulation was used to model a neutron tracker developed to track secondary neutrons produced in proton therapy [93]. This would help in better modeling of secondary neutrons.

\section{THERANOSTICS USING RADIOACTIVE ISOTOPES}

Feasibility of radioactive ion beams ${ }^{10,11} \mathrm{C},{ }^{13} \mathrm{~N},{ }^{14,15} \mathrm{O},{ }^{17,18} \mathrm{~F}$ and ${ }^{18,19} \mathrm{Ne}$ was investigated [50, 94-96] and reviewed [97] for inbeam positron emission tomography imaging in ion therapy. In the case of ${ }^{11} \mathrm{C}$ and ${ }^{15} \mathrm{O}$, the difference in the Bragg peak position and the position of the maximum positron emitting fragments was negligible for ideal monoenergetic beams, but this difference increased with and was strongly influenced by the energy spread of the primary beams [94]. The difference also increased with energy of the primary beam. For $250 \mathrm{MeV} / \mathrm{u}{ }^{15} \mathrm{O}$ and $350 \mathrm{MeV} / \mathrm{u}$ ${ }^{11} \mathrm{C}$ beams, the measured differences of 2.0 and $4.4 \mathrm{~mm}$, respectively, were well reproduced by the PHITS simulations. Of the radioactive ion beams mentioned above, ${ }^{15} \mathrm{O}$ turned out to have the best feasibility for in-beam imaging and range monitoring [50].

Another set of isotopes emerging as potential diagnostic and therapeutic nuclides are the two radioisotopes of $\mathrm{Cu}-{ }^{62,64} \mathrm{Cu}[95$, 96, 98-107]. $\mathrm{Cu}$ is one of the most abundant trace transition elements in human body and plays a key role in various physiological processes. Among the five radioisotopes of $\mathrm{Cu}$, 
namely, ${ }^{60,61,62,64,67} \mathrm{Cu},{ }^{62} \mathrm{Cu}$ (half-life $9.67 \mathrm{~min}$ ) decays by $\beta+$ emission and is used for diagnosis. ${ }^{64} \mathrm{Cu}$ with a half-life of $12.7 \mathrm{~h}$ decays by electron capture $\beta+$ and $\beta$-emission. Electron capture results in the emission of Auger electrons which can be used for therapy [100]. So ${ }^{64} \mathrm{Cu}$ is increasingly investigated for use in diagnosis as well as in therapy. In normal cells, $\mathrm{Cu}$ remains in the cytoplasm, but in tumor cells it migrates to the nucleus [98]. Thus, ${ }^{64} \mathrm{Cu}$ can be used for theranostics without causing toxicity to the normal cell. The effect of ${ }^{64} \mathrm{CuCl}_{2}$ on human glioblastoma multiforme cell lines was studied by Catalogna et al. [101]. This study supported the theranostic potential of ${ }^{64} \mathrm{CuCl}_{2}$ in this tumor. ${ }^{64} \mathrm{CuCl}_{2}$ could be efficiently used for PET imaging in glioblastoma multiforme [102] which supported the prospect of ${ }^{64} \mathrm{Cu}$ as a diagnostic isotope for tumors of central nervous system. ${ }^{64} \mathrm{CuCl}_{2}$ as a PET probe with PET-CT imaging could be efficiently used for determining the stage of prostate cancer in the works of Capasso et al. [103]. ${ }^{64} \mathrm{Cu}$-ATSM radiopharmaceutical was studied for imaging of hypoxic tumor tissue. A difference between normal and hypoxic cells was revealed around $10-15 \mathrm{~min}$ after administration of the compound [104]. Efficacy of ${ }^{64} \mathrm{Cu}$-labelledDOTATATE was investigated for imaging of neuroendocrine tumors. High spatial resolution, very good image quality, and significantly improved lesion detection capability were observed compared to ${ }^{111}$ In-DTPA-octreotide [105] and ${ }^{68} \mathrm{Ga}$-DOTATOC [106], respectively. ${ }^{64} \mathrm{Cu}$ was also used to study the uptake of specific antibody in patients with metastatic or advanced primary colorectal cancer. It showed higher specificity than ${ }^{18} \mathrm{~F}-\mathrm{FDG}$ for detection of colorectal tumors [107]. Feasibility of ${ }^{64} \mathrm{Cu}$-labelled receptor antibody was studied for early detection and image-guided surgery of pancreatic cancers and gastrointestinal cancer using PET imaging [94, 95]. It was observed that pancreatic tumors larger than $3 \mathrm{~mm}$ could be detected and well resected [94]. Biodistribution and radiation dosimetry studies of ${ }^{64} \mathrm{CuCl}_{2}$ showed that liver has the highest uptake of ${ }^{64} \mathrm{Cu}$ in this form [108]. This was followed by intestine and pancreas. It was suggested that therapeutic activity with ${ }^{64} \mathrm{Cu}$ (in chloride form) up to several GBq would be safely feasible for these organs.

Several nuclides mentioned above are prospective candidates for theranostic applications-there are a few bottlenecks though. For radionuclides, the specific characteristics required for good imaging are different from those required for treatment. So only a few isotopes, for instance, ${ }^{64} \mathrm{Cu}$, offer a combination of diagnostic and therapeutic capability. Secondly, phenotype-specific radiopharmaceutical is required for theranostic applications [109]. There are difficulties also related to dosimetry and delivery of the radionuclides to the target tissue. The drug compound may not be distributed uniformly in the target volume, and dose assessment is a complex task [110]. Moreover, theranostic application requires cost-effective supply of radioisotopes, clinical and regulatory approval of radiopharmaceuticals, and trained, competent manpower.

\section{CONCLUSION}

Ion therapy has emerged as one of the preferred methods of treatment in certain indications of malignancy. Detailed studies by different authors showed that the secondary radiation produced by the beam interaction in the patient's body can be used for range correlation and fine tuning of the primary beam. ${ }^{16} \mathrm{O}$ was detected to be the optimum among stable beams for range monitoring using annihilation gammas from positron emitting fragments. Prompt gammas and SCPs could be employed for monitoring the range of the primary beam with millimetric precision. This will help to determine the actual volume where the dose is deposited. On the other hand, the secondary radiation also causes dose deposition outside the target volume. This secondary radiation includes SCPs (from projectile and target fragmentation and particle emission), neutrons, and prompt gamma radiation. Neutrons produced in the patient's body may cause exposure to some healthy tissue well outside the target volume, though the dose would be small, whereas in photon therapy a large volume of healthy tissue is exposed to significant amount of radiation dose from the primary beam itself. Thus, the probability of secondary radiogenic cancer is decreased in ion therapy compared to that in the case of photon therapy. The neutron ambient dose equivalent $\mathrm{H}_{n}^{*}$ (10) in passive scanning method is substantially higher than that for active scanned beam. Among all the SCPs produced, light charged particles have the highest yield and show a broad angular distribution. Heavier fragments have lower yield and are confined to a narrow cone. In theranostics using radioactive beam, new isotopes are being investigated in detail by several authors. Of these, ${ }^{15} \mathrm{O}$ has appeared as a good candidate for in-beam PET imaging and range monitoring. ${ }^{64} \mathrm{Cu}$ in its ionic form as ${ }^{64} \mathrm{CuCl}_{2}$ has good prospect as a diagnostic agent for tumors of central nervous system, hypoxic tumors, and prostate cancer. ${ }^{64} \mathrm{Cu}$-labelled radiopharmaceuticals are effective in imaging of neuroendocrinal tumors and colorectal cancer. Annihilation gammas from the positron emitting isotope ${ }^{64} \mathrm{Cu}$ could be efficiently used for image-guided surgery in pancreatic and gastrointestinal cancer. Prospective isotopes for theranostics need to be studied in great detail in order to come up with the most effective choices.

\section{Review Criteria}

Data for this review are compiled searching the published literature including archived works with no limitation on date. Searched phrases include "ion therapy", "particle therapy", "secondary radiation", "neutrons", "theranostics", among others. References have been quoted for all the works mentioned.

\section{AUTHOR CONTRIBUTIONS}

The author confirms being the sole contributor of this work and has approved it for publication.

\section{FUNDING}

The work has been carried out under the XII plan project "Biomolecular Architecture Recognition and Dynamics (BARD)" of Saha Institute of Nuclear Physics, Department of Atomic Energy, Kolkata, Govt. of India. 


\section{REFERENCES}

1. Durante M, Cucinotta FA, Loeffler JS Editorial: Charged particles in oncology. Front Oncol (2017) 7:301. doi:10.3389/fonc.2017.00301

2. Malouff TD, Mahajan A, Krishnan S, Beltran C, Seneviratne DS, Trifiletti DM Carbon ion therapy: A modern review of an emerging technology. Front Oncol (2020) 10:82. doi:10.3389/fonc.2020.00082

3. Durante M, Debus J Heavy charged particles: does improved precision and higher biological effectiveness translate to better outcome in patients? Semin Radiat Oncol (2018) 28(2):160-67. doi:10.1016/j.semradonc.2017. 11.004

4. Durante M, Formenti S Harnessing radiation to improve immunotherapy: better with particles? Br J Radiol (2020) 93(1107):20190224. doi:10.1259/bjr. 20190224

5. van der Horst A, Houweling AC, van Tienhoven G, Visser J, Bel A Dosimetric effects of anatomical changes during fractionated photon radiation therapy in pancreatic cancer patients. J Appl Clin Med Phys (2017) 18(6):142-51. doi:10. $1002 / \mathrm{acm} 2.12199$

6. Yokoyama A, Kubota Y, Kawamura H, Miyasaka Y, Kubo N, Sato H, et al. Impact of inter-fractional anatomical changes on dose distributions in passive carbon-ion radiotherapy for prostate cancer: comparison of vertical and horizontal fields. Front Oncol (2020) 10:1264. doi:10.3389/fonc.2020. 01264

7. Sterzing F, Engenhart-Cabillic R, Flentje M, Debus J Image-guided radiotherapy: a new dimension in radiation oncology. Dtsch Arztebl Int (2011) 108(16):274-80. doi:10.3238/arztebl.2011.0274

8. Jeelani S, Jagat Reddy RC, Maheswaran T, Asokan GS, Dany A, Anand B Theranostics: A treasured tailor for tomorrow. J Pharm BioAllied Sci (2014) 6(Suppl. 1):S6-S8. doi:10.4103/0975-7406.137249

9. Eley JG, Friedrich T, Homann KL, Howell RM, Scholz M, Durante M, et al. Comparative risk predictions of second cancers after carbon-ion therapy versus proton therapy. Int J Radiat Oncol Biol Phys (2016) 95(1):279-86. doi:10.1016/j. ijrobp.2016.02.032

10. Durante M, Paganetti H Nuclear physics in particle therapy: a review. Rep Prog Phys (2016) 79:096702. doi:10.1088/0034-4885/79/9/096702

11. Battistoni G, Mattei I, Muraro S Nuclear physics and particle therapy. Adv Phys $X(2016)$ 1(4):661. doi:10.1080/23746149.2016.1237310

12. Kodaria S, Kitamura H, Kurano M, Kawashima H, Benton ER Contribution to dose in healthy tissue from secondary target fragments in therapeutic proton, $\mathrm{He}$ and C beams measured with CR-39 plastic nuclear track detectors. Sci Rep (2019) 9(1):3708. doi:10.1038/s41598-019-39598-0

13. Kodaira S, Konishi T, Kitamura H, Kurano M, Kawashima H, Uchihori Y, et al. On the use of CR-39 PNTD with AFM analysis in measuring protoninduced target fragmentation particles. Nucl Instrum Methods Phys Res Sect B Beam Interact Mater Atoms (2015) 349:163. doi:10.1016/j.nimb. 2015.02.052

14. Rucinski A, Traini G, Roldan AB, Battistoni G, De Simoni M, Dong Y, et al. Secondary radiation measurements for particle therapy applications: charged secondaries produced by ${ }^{16} \mathrm{O}$ ion beams in a PMMA target at large angles. Phys Med (2019) 64:45-53. doi:10.1016/j.ejmp.2019.06.001

15. Tinganelli W, Durante M, Hirayama R, Krämer M, Maier A, Kraft-Weyrather W, et al. Kill-painting of hypoxic tumours in charged particle therapy. Sci Rep (2015) 5:17016. doi:10.1038/srep17016

16. Piersanti L, Bellini F, Bini F, Collamati F, De Lucia E, Durante M, et al. Measurement of charged particle yields from PMMA irradiated by a $220 \mathrm{MeV} /$ u (12)C beam. Phys Med Biol (2014) 59(7):1857-72. doi:10.1088/0031-9155/ $59 / 7 / 1857$

17. Gwosch K, Hartmann B, Jakubek J, Granja C, Soukup P, Jäkel O, et al. Noninvasive monitoring of therapeutic carbon ion beams in a homogeneous phantom by tracking of secondary ions. Phys Med Biol (2013) 58(11): 3755-73. doi:10.1088/0031-9155/58/11/3755

18. Granja C, Martisikova M, Jakubek J, Opalka L, Gwosch K Imaging and characterization of primary and secondary radiation in ion beam therapy. AIP Conf Proc (2016) 1753:080007. doi:10.1063/1.4955377

19. Paganetti $\mathrm{H}$ Nuclear interactions in proton therapy: dose and relative biological effect distributions originating from primary and secondary particles. Phys Med Biol (2002) 47:747. doi:10.1088/0031-9155/47/5/305
20. Cucinotta FA, Katz R, Wilson JW, Townsend LW, Shinn J, Hajnal F Biological effectiveness of high-energy protons: target fragmentation. Radiat Res (1991) 127(2):130-7. doi:10.2307/3577956

21. Tommasino F, Durante M Proton radiobiology. Cancers (2015) 7:353. doi:10. 3390/cancers7010353

22. Golovchenko AN, Skvarč J, Yasuda N, Giacomelli M, Tretyakova SP, Ilic R, et al. Erratum: total charge-changing and partial cross-section measurements in the reactions of $110-250 \mathrm{MeV} /$ nucleon $12 \mathrm{C}$ in carbon, paraffin, and water. Phys Rev C (2002) 66(1):014609. doi:10.1103/physrevc.66.014609

23. Toshito T, Kodama K, Sihver L, Yusa K, Ozaki M, Kameoka AS, et al. Measurements of total and partial charge-changing cross sections for 200to $400-\mathrm{MeV}$ /nucleaon $12 \mathrm{C}$ on water and polycarbonate. Phys Rev C (2007) 75(5):054606. doi:10.1103/PhysRevC.75.054606

24. Schall I, Schardt D, Geissel H, Irnich H, Kankeleit E, Kraft G, et al. Chargechanging nuclear reactions of relativistic light-ion beams $(5 \leq \mathrm{Z} \leq 10)$ passing through thick absorbers. Nucl Instrum Methods Phys Res Sect B Beam Interact Mater Atoms (1996) 117(3):221-34. doi:10.1016/0168-583x(96)00325-4

25. Dudouet J, Juliani D, Labalme M, Cussol D, Angelique JC, Braunn B, et al. Double-differential fragmentation cross-section measurements of $95 \mathrm{MeV} /$ nucleon 12C beams on thin targets for hadron therapy. Phys Rev C (2013) 88 : 024606. doi:10.1103/PhysRevC.88.024606

26. Mattei I, Alexandrov A, Alunni Solestizi L, Ambrosi G, Argiro S, Bartosik N, et al. Measurement of $12 \mathrm{C}$ fragmentation cross sections on $\mathrm{C}, \mathrm{O}$, and $\mathrm{H}$ in the energy range of interest for particle therapy applications. IEE Trans Radiat Plasma Med Sci (2020) 4(2):269-82. doi:10.1109/TRPMS.2020.2972197

27. Agodi C, Battistoni G, Bellini F, Cirrone GAP, Collamati F, Cuttone G, et al. Charged particle's flux measurement from PMMA irradiated by $80 \mathrm{MeV} / \mathrm{u}$ carbon ion beam. Phys Med Biol (2012) 57(18):5667-78. doi:10.1088/0031$9155 / 57 / 18 / 5667$

28. Gunzert-Marx K, Iwase H, Schardt D, Simon RS Secondary beam fragments

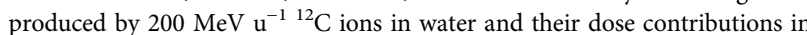
carbon ion radiotherapy. New J Phys (2008) 10(7):075003. doi:10.1088/13672630/10/7/075003

29. Braunn B, Labalme M, Ban G, Chevallier M, Colin J, Cussol D, et al. Nuclear reaction measurements of $95 \mathrm{MeV} / \mathrm{u}{ }^{12} \mathrm{C}$ interactions on PMMA for hadrontherapy. Nucl Instrum Methods Phys Res Sect B Beam Interact Mater Atoms (2011) 269(22):2676-84. doi:10.1016/j.nimb.2011.08.010

30. Haettner E, Iwase H, Krämer M, Kraft G, Schardt D Experimental study of nuclear fragmentation of 200 and $400 \mathrm{MeV} / \mathrm{u} 12 \mathrm{C}$ ions in water for applications in particle therapy. Phys Med Biol (2013) 58(23):8265-79. doi:10.1088/0031$9155 / 58 / 23 / 8265$

31. Matsufuji N, Fukumura A, Komori M, Kanai T, Kohno T Influence of fragment reaction of relativistic heavy charged particles on heavy-ion radiotherapy. Phys Med Biol (2003) 48(11):1605-23. doi:10.1088/00319155/48/11/309

32. De Lellis G, Buontempo S, Di Capua F, Di Crescenzo A, Migliozzi P, Petukhov $\mathrm{Y}$, et al. Measurement of the fragmentation of Carbon nuclei used in hadrontherapy. Nucl Phys A (2011) 853(1):124-34. doi:10.1016/j.nuclphysa.2011. 01.019

33. Haettner E, Iwase H, Schardt D Experimental fragmentation studies with ${ }^{12} \mathrm{C}$ therapy beams. Radiat Prot Dosimetry (2006) 122:485-7. doi:10.1093/rpd/ ncl402

34. Greilich S, Ulrich L, Kouwenberg JJM, Rahmanian S Measurement of fluence, LET, and dose in a carbon ion spread-out Bragg-peak using fluorescent nuclear track detectors and an automated reader. arXiv:1610.05054v3 (Forthcoming 2017).

35. Matsufuji N, Komori M, Sasaki H, Akiu K, Ogawa M, Fukumura A, et al. Spatial fragment distribution from a therapeutic pencil-like carbon beam in water. Phys Med Biol (2005) 50(14):3393-403. doi:10.1088/0031-9155/50/ $14 / 014$

36. Golosio B, Gadow K, Goettlich M, Silenzi A, Xu C Single channel optimization for an endoscopic time-of-flight positron emission tomography detector. In: NSS/MIC'11: IEEE nuclear science symposym conference record, 2011 Oct 23-29, Valencia, Spain. IEEE (2011). p. 2277.

37. Golovkov M, Aleksandrov D, Chulkov L, Kraus G, Schardt D, et al. Advances in Hadrontherapy. In: U Amaldi, B Larsson, Y Lemoigne, editors Excerpta medica international congress series, Vol 1144, Amsterdam, Netherland: Elsevier (1997). p. 316. 
38. Aleksandrov A, Consiglio L, De Lellis G, Di Crescenzo A, Lauria A, Montesi $\mathrm{MC}$, et al. Measurement of large angle fragments induced by $400 \mathrm{MeV}$ $\mathrm{n}-1$ carbon ion beams. Meas Sci Technol (2015) 26(9):094001. doi:10.1088/ 0957-0233/26/9/094001

39. Schardt D, Schall I, Geissel H, Irnich H, Kraft G, Magel A, et al. Nuclear fragmentation of high-energy heavy-ion beams in water. Adv Space Res (1996) 17(2):87-94. doi:10.1016/0273-1177(95)00516-H

40. Bethe H Zur theorie des durchgangs schneller korpuskularstrahlen durch materie. Ann Phys (1930) 397(3) 325-400. doi:10.1002/andp.19303970303

41. Rucinski A, De Lucia E, Battistoni G, Collamati F, Faccini R, et al. Secondary radiation measurements for particle therapy applications: Charged secondaries produced by $4 \mathrm{He}$ and $12 \mathrm{C}$ ion beams in a PMMA target at large angle (2016). Available from: arXiv:1608.04624v1 (Accessed August 16, 2016).

42. Rucinski A, Battistoni G, Collamati F, De Lucia E, Faccini R, Frallicciardi PM, et al. Secondary radiation measurements for particle therapy applications: charged particles produced by ${ }^{4} \mathrm{He}$ and ${ }^{12} \mathrm{C}$ ion beams in a PMMA target at large angle. Phys Med Biol (2018) 63(5):055018. doi:10. 1088/1361-6560/aaa36a

43. Marafini M, Paramatti R, Pinci D, Battistoni G, Collamati F, De Lucia E, et al. Secondary radiation measurements for particle therapy applications: nuclear fragmentation produced by ${ }^{4} \mathrm{He}$ ion beams in a PMMA target. Phys Med Biol (2017) 62(4):1291-1309. doi:10.1088/1361-6560/aa5307

44. Toppi M, Battistoni G, Bellini F, Collamati F, De Lucia E, Durante M, et al. Measurement of secondary particle production induced by particle therapy ion beams impinging on a PMMA target. EPJ Web Conf (2016) 117:05007. doi:10. 1051/epjconf/201611705007

45. Maccabee HD, Ritter MA Fragmentation of high-energy oxygen-ion beams in water. Radiat Res (1974) 60:409-21. doi:10.2307/3574021

46. Schimmerling W, Miller J, Wong M, Rapkin M, Howard J, Spieler HG, et al. The fragmentation of $670 \mathrm{~A} \mathrm{MeV}$ neon-20 as a function of depth in water: I. Experiment. Radiat Res (1989) 120(1):36-71. doi:10.2307/3577634

47. Inaniwa $\mathrm{T}$, Kanematsu N, Noda K, Kamada $\mathrm{T}$ Treatment planning of intensity modulated composite particle therapy with dose and linear energy transfer optimization. Phys Med Biol (2017) 62(12):5180-197. doi:10.1088/1361-6560/ aa68d7

48. Noda K Progress of radiotherapy technology with HIMAC. J Phys Conf Ser (2019) 1154:012019. doi:10.1088/1742-6596/1154/1/012019

49. Rovituso M, Schuy C, Weber U, Brons S, Cortés-Giraldo MA, La Tessa C, et al. Fragmentation of 120 and $200 \mathrm{MeV} \mathrm{u}^{-14} \mathrm{He}$ ions in water and PMMA targets. Phys Med Biol (2017) 62(4):1310-26. doi:10.1088/1361-6560/aa5302

50. Inaniwa $T$, Tomitani $T$, Kohno $T$, Kanai $T$ Quantitative comparison of suitability of various beams for range monitoring with induced $\beta$ +activity in hadron therapy. Phys Med Biol (2005) 50(6):1131-45. doi:10.1088/0031$9155 / 50 / 6 / 007$

51. Nishio T, Ogino T, Nomura K, Uchida H Dose-volume delivery guided proton therapy using beam on-line PET system. Med Phys (2006) 33(11):4190-7. doi:10.1118/1.2361079

52. Nishio T, Miyatake A, Ogino T, Nakagawa K, Saijo N, Esumi H The development and clinical use of a beam ON-LINE PET system mounted on a rotating gantry port in proton therapy. Int J Radiat Oncol Biol Phys (2010) 76(1):277-86. doi:10.1016/j.ijrobp.2009.05.065

53. Min C-H, Kim CH, Youn M-Y, Kim J-W Prompt gamma measurements for locating the dose falloff region in the proton therapy. Appl Phys Lett (2006) 89(18):183517. doi:10.1063/1.2378561

54. Pinto M, Bajard M, Brons S, Chevallier M, Dauvergne D, Dedes G, et al. Absolute prompt-gamma yield measurements for ion beam therapy monitoring. Phys Med Biol (2015) 60(2):565-94. doi:10.1088/0031-9155/60/ $2 / 565$

55. Testa E, Bajard M, Chevallier M, Dauvergne D, Le Foulher F, Freud N, et al. Dose profile monitoring with carbon ions by means of prompt-gamma measurements. Nucl Instrum Meth B (2009) 267(6):993-6. doi:10.1016/j. nimb.2009.02.031

56. Roellinghoff F, Benilov A, Dauvergne D, Dedes G, Freud N, Janssens G, et al. Real-time proton beam range monitoring by means of prompt-gamma detection with a collimated camera. Phys Med Biol (2014) 59(5):1327-38. doi:10.1088/0031-9155/59/5/1327
57. Kelleter L, Wrońska A, Besuglow J, Konefał A, Laihem K, Leidner J, et al. Spectroscopic study of prompt-gamma emission for range verification in proton therapy. Phys Med (2017) 34:7-17. doi:10.1016/j.ejmp.2017.01.003

58. Krimmer J, Dauvergne D, Létang JM, Testa É Prompt-gamma monitoring in hadronthreapy: a review. Nucl Inst Meth Phys Res A (2017) 878:58-73. doi:10. 1016/j.nima.2017.07.063

59. Henriquet P, Testa E, Chevallier M, Dauvergne D, Dedes G, Freud N, et al. Interaction vertex imaging (IVI) for carbon ion therapy monitoring: a feasibility study. Phys Med Biol (2012) 57(14):4655-69. doi:10.1088/00319155/57/14/4655

60. Muraro S, Battistoni G, Collamati F, De Lucia E, Faccini R, Ferroni F, et al. Monitoring of hadrontherapy treatments by means of charged particle detection. Front Oncol (2016) 6:177. doi:10.3389/fonc.2016.00177

61. Agostinelli S, Allison J, Amako K, Apostolakis J, Araujo H, Arce P, et al. GEANT4-a simulation toolkit. Nucl Instr Meth Phys Res A (2003) 506(3): 250-303. doi:10.1016/S0168-9002(03)01368-8

62. Johnson D, Chen Y, Ahmad S Dose and linear energy transfer distributions of primary and secondary particles in carbon ion radiation therapy: a monte carlo simulation study in water. J Med Phys (2015) 40(4):214-9. doi:10.4103/09716203.170785

63. Ying C, Bolst D, Rosenfeld A, Guatelli S Characterization of the mixed radiation field produced by carbon and oxygen ion beams of therapeutic energy: a Monte Carlo simulation study. J Med Phys (2019) 44(4):263-69. doi:10.4103/jmp.jmp_40_19

64. Hirano Y, Kodaira S, Souda H, Osaki K, Torikoshi M Estimations of relative biological effectiveness of secondary fragments in carbon ion irradiation of water using CR-39 plastic detector and microdosimetric kinetic model. Med Phys (2020) 47(2):781-9. doi:10.1002/mp.13916

65. Hirano Y, Kodaira S, Souda H, Matsumura A, Torikoshi M Linear energy transfer (LET) spectra and survival fraction distribution based on the CR-39 plastic charged-particle detector in a spread-out Bragg peak irradiation by a ${ }^{12} \mathrm{C}$ beam. Phys Med Biol (2018) 63(18):185006. doi:10.1088/1361-6560/aadaa6

66. Mancini-Terracciano C, Caccia B, Colonna M, De Napoli M, Dotti A, Faccini $\mathrm{R}$, et al. Validation of Geant4 nuclear reaction models for hadron therapy and preliminary results with BLOB. In: World congress on medical physics and biomedical engineering. IFMBE proceedings; 2018 Jun 3-8; Prague, Czech Republic, Vol 68, Singapore: Springer Singapore (2019). p. 675-85.

67. Bolst D, Cirrone GAP, Cuttone G, Folger G, Incerti S, Ivanchenko V, et al. Validation of Geant4 fragmentation for heavy ion therapy. Nucl Instum Meth Phys Res A (2017) 869:68-75. doi:10.1016/j.nima.2017.06.046

68. Ying CK, Bolst D, Tran LT, Guatelli S, Rosenfeld AB, Kamil WA, et al. Contributions of secondary fragmentation by carbon ion beams in water phantom: Monte Carlo simulation. J Phys: Conf Ser (2017) 851:012033. doi:10. 1088/1742-6596/851/1/012033

69. Niita K, Sato T, Iwase H, Nose H, Nakashima H, Sihver L PHITS-a particle and heavy ion transport code system. Radiat Meas (2006) 41(9-10):1080-90. doi:10.1016/j.radmeas.2006.07.013

70. Zeitlin C, La Tessa C The role of nuclear fragmentation in particle therapy and space radiation protection. Front Oncol (2016) 6:65. doi:10.3389/fonc.2016.00065

71. Puchalska M, Tessonnier T, Parodi K, Sihver L Benchmarkin of PHITS for carbon ion therapy. Int J Part Ther (2018) 4(3):48-55. doi:10.14338/IJPT-1700029.1

72. Battistoni G, Boehlen T, Cerutti F, Chin PW, Esposito LS, et al. Overview of the FLUKA code. Ann Nucl Energy (2015) 82:10-8. doi:10.1016/j.anucene.2014.11. 007, T. T. Bohlen, F. Cerutti, M. P. W. Chin, A. Fassò, A. Ferrari, et al. Nucl. Data Sheets 120 (2014) 211.

73. Embriaco A, Dong Y, Mattei I, Muraro S, Valle SM, Battistoni G Target fragmentation in proton therapy. Il Nuovo Cimento C (2018) 41(6):207. doi:10. 1393/ncc/i2018-18207-4

74. Dedes G, Parodi K Monte carlo simulations of particle interactions with tissue in carbon ion therapy. Int J Part Ther (2015) 2(3):447-58. doi:10.14338/IJPT15-00021

75. Howell RM, Kry SF, Burgett E, Hertel NE, Followill DS Secondary neutron spectra from modern Varian, Siemens, and Elekta linacs with multileaf collimators. Med Phys (2009) 36(9):4027-38. doi:10.1118/1.3159300

76. Prez-Andujar A, Newhauser WD, DeLuca PM. Nucl Technol (2010) 55:7009. 
77. Schardt D, Elsässer T, Schulz-Ertner D Heavy-ion tumor therapy: physical and radiobiological benefits. Rev Mod Phys (2010) 82:383. doi:10.1103/ RevModPhys.82.383

78. Xu G, Bednarz B, Paganetti H A review of dosimetry studies on external-beam radiation treatment with respect to second cancer induction. Phys Med Biol (2008) 53(13):R193. doi:10.1088/0031-9155/53/13/R01

79. Pérez-Andújar A, Newhauser WD, DeLuca PM Neutron production from beam-modifying devices in a modern double scattering proton therapy beam delivery system. Phys Med Biol (2009) 54(4):993-1008. doi:10.1088/00319155/54/4/012

80. Nandy M, Sarkar PK, Sanami T, Takada M, Shibata T Neutron emission and dose distribution from natural carbon irradiated with a $12 \mathrm{MeV} \mathrm{amu}{ }^{-1}{ }^{12} \mathrm{C}^{5+}$ ion beam. J Radiol Prot (2016) 36(3):456. doi:10.1088/0952-4746/36/3/456

81. Mares V, Romero-Expósito M, Farah J, Trinkl S, Domingo C, Dommert M, et al. A comprehensive spectrometry study of a stray neutron radiation field in scanning proton therapy. Phys Med Biol (2016) 61(11):4127-40. doi:10.1088/ 0031-9155/61/11/4127

82. Trinkl S, Mares V, Englbrecht FS, Wilkens JJ, Wielunski M, Parodi K, et al. Systematic out-of-field secondary neutron spectrometry and dosimetry in pencil beam scanning proton therapy. Med Phys (2017) 44(5):1912-20. doi: $10.1002 / \mathrm{mp} .12206$

83. Farah J, Mares V, Romero-Expósito M, Trinkl S, Domingo C, Dufek V, et al. Measurement of stray radiation within a scanning proton therapy facility: EURADOS WG9 intercomparison exercise of active dosimetry systems. Med Phys (2015) 42(5):2572. doi:10.1118/1.4916667

84. Yonai S, Matsufuji N, Kanai T, Matsui Y, Matsushita K, Yamashita H, et al. Measurement of neutron ambient dose equivalent in passive carbon-ion and proton radiotherapies. Med Phys (2008) 35(11):4782-92. doi:10.1118/1. 2989019

85. Yonai S, Furukawa T, Inaniwa $\mathrm{T}$ Measurement of neutron ambient dose equivalent in carbon-ion radiotherapy with an active scanned delivery system. Radiat Prot Dosimetry (2014) 161(1-4):433-6. doi:10.1093/rpd/nct251

86. Howell RM, Burgett EA Secondary neutron spectrum from $250-\mathrm{MeV}$ passively scattered proton therapy: measurement with an extended-range Bonner sphere system. Med Phys (2014) 41(9):092104. doi:10.1118/1.4892929

87. La Tessa C, Berger T, Kaderka R, Schardt D, Burmeister S, Labrenz J, et al. Characterization of the secondary neutron field produced during treatment of an anthropomorphic phantom with x-rays, protons and carbon ions. Phys Med Biol (2014) 59(8):2111-25. doi:10.1088/0031-9155/59/8/2111

88. Takam R, Bezak E, Marcu LG, Yeoh E Out-of-field neutron and leakage photon exposures and the associated risk of second cancers in high-energy photon radiotherapy: current status. Radiat Res (2011) 176(4):508-20. doi:10. 1667/RR2606.1

89. Kaderka R, Schardt D, Durante M, Berger T, Ramm U, Licher J, et al. Out-offield dose measurements in a water phantom using different radiotherapy modalities. Phys Med Biol (2012) 57(16):5059-74. doi:10.1088/0031-9155/57/ $16 / 5059$

90. La Tessa C, Berger T, Kaderka R, Schardt D, Körner C, Ramm U, et al. Out-offield dose studies with an anthropomorphic phantom: comparison of X-rays and particle therapy treatments. Radiother Oncol (2012) 105(1):133-8. doi:10. 1016/j.radonc.2012.04.004

91. Douglass M, Bezak E Physical modelling of proton and heavy ion radiation using Geant4. EPJ Web Conf (2012) 35:04001. doi:10.1051/epjconf/ 20123504001

92. Schneider U, Hälg R The impact of neutrons in clinical proton therapy. Front Oncol (2015) 5:235. doi:10.3389/fonc.2015.00235

93. Gioscio E, Battistoni G, Bochetti A, De Simoni M, Dong Y, Fischetti M, et al. Development of a novel neutron tracker for the characterisation of secondary neutrons emitted in particle therapy. Nucl Inst Meth Phys Res A (2019) 958: 162862. doi:10.1016/j.nima.2019.162862

94. Mohammadi A, Tashima H, Iwao Y, Takyu S, Akamatsu G, Nishikido F, et al. Range verification of radioactive ion beams of ${ }^{11} \mathrm{C}$ and ${ }^{15} \mathrm{O}$ using in-beam PET imaging. Phys Med Biol (2019) 64(14):145014. doi:10.1088/1361-6560/ab25ce

95. Yoshii Y, Tashima H, Iwao Y, Yoshida E, Wakizaka H, Akamatsu G, et al. Immuno-OpenPET: a novel approach for early diagnosis and image-guided surgery for small resectable pancreatic cancer. Sci Rep (2020) 10(1):4143. doi:10.1038/s41598-020-61056-5
96. Yoshii Y, Yoshimoto M, Matsumoto H, Tashima H, Iwao Y, Takuwa H, et al. Integrated treatment using intraperitoneal radioimmunotherapy and positron emission tomography-guided surgery with ${ }^{64} \mathrm{Cu}$-labeled cetuximab to treat early- and late-phase peritoneal dissemination in human gastrointestinal cancer xenografts. Oncotarget (2018) 9(48):28935-50. doi:10.18632/ oncotarget.25649

97. Durante M, Parodi K Radioactive beams in particle therapy: past, present, and future. Front Phys (2020) 8:00326. doi:10.3389/fphy.2020.00326

98. Gutfilen B, Souza S, Valentini G Copper-64: a real theranostic agent. Drug Des Dvel Ther (2018) 12:3235-45. doi:10.2147/DDDT.S170879

99. Boschi A, Martini P, Janevik-Ivanovska E, Duatti A The emerging role of copper-64 radiopharmaceuticals as cancer theranostics. Drug Discov Today (2018) 23(8):1489-1501. doi:10.1016/j.drudis.2018.04.002

100. Righi S, Ugolini M, Bottoni G, Puntoni M, Lacozzi M, Paparo F, et al. Biokinetic and dosimetric aspects of ${ }^{64} \mathrm{CuCl}_{2}$ in human prostate cancer: possible theranostic implications. EJNMMI Res (2018) 8(1):18. doi:10.1186/ s13550-018-0373-9

101. Catalogna G, Talarico C, Dattilo V, Gangemi V, Calabria F, D’Antona L, et al. The SGK1 kinase inhibitor SI113 sensitizes theranostic effects of the $64 \mathrm{CuCl} 2$ in human glioblastoma multiforme cells. Cell Physiol Biochem (2017) 43(1): 108-19. doi:10.1159/000480328

102. Panichelli P, Villano C, Cistaro A, Bruno A, Barbato F, Piccardo A, et al. Imaging of brain tumors with copper-64 chloride: early experience and results. Canc Biother Rad (2016) 31(5):159-67. doi:10.1089/cbr.2016.2028

103. Capasso E, Durzu S, Piras S, Zandieh S, Knoll P, Haug A, et al. Role of (64) $\mathrm{CuCl} 2 \mathrm{PET} / \mathrm{CT}$ in staging of prostate cancer. Ann Nucl Med (2015) 29(6) 482-8. doi:10.1007/s12149-015-0968-4

104. Bourgeois M, Rajerison H, Guerard F, Mougin-Degraef M, Barbet J, Michel $\mathrm{N}$, et al. Contribution of [64Cu]-ATSM PET in molecular imaging of tumour hypoxia compared to classical [18F]-MISO - a selected review. Nucl Med Rev Cent East Eur (2011) 14(2):90-5. doi:10.5603/nmr.2011.00022

105. Pfeifer A, Knigge U, Mortensen J, Oturai P, Berthelsen AK, Loft A, et al. Clinical PET of neuroendocrine tumors using 64Cu-DOTATATE: first-inhumans study. J Nucl Med (2012) 53(8):1207-15. doi:10.2967/jnumed.111. 101469

106. Johnbeck CB, Knigge UA, Loft A, Berthelsen AK, Mortensen J, Oturai P, et al. Head-to-Head comparison of ${ }^{64} \mathrm{Cu}$-DOTATATE and ${ }^{68} \mathrm{Ga}$-DOTATAC PET/ CT: a prospective study of 59 patients with neuroendocrine tumors. $\mathrm{J} \mathrm{Nucl}$ Med (2017) 58(3):451-57. doi:10.2967/jnumed.116.180430

107. Philpott GW, Schwarz SW, Anderson CJ, Dehdashti F, Connett JM, Zinn KR, et al. RadioimmunoPET: detection of colorectal carcinoma with positronemitting copper-64-labeled monoclonal antibody. J Nucl Med (1995) 36(10): $1818-24$.

108. Avila-Rodriguez MA, Rios C, Carrasco-Hernandez J, Manrique-Arias JC, Martinez-Hernandez R, Garciá-Pérez FO, et al. Biodistribution and radiation dosimetry of $\left[{ }^{64} \mathrm{Cu}\right]$ copper dichloride: first-in-human study in healthy volunteers. EJNMMI Res (2017) 7(1):98. doi:10.1186/s13550-0170346-4

109. Kraeber-Bodéré F, Barbet J Challenges in nuclear medicine: innovative theranostic tools for personalized medicine. Front Med (2014) 1:16. doi:10.3389/fmed.2014.00016

110. Buscombe J Therapeutic nuclear medicine in the United Kingdom. In: R McCready, G Gnanasegaran, J Bomanji, editors A history of radionuclide studies in the United Kingdom: 50th anniversary of the british nuclear medicine society. Chap. 16, Cham, Switzerland: Springer (2016). p. 121-8. doi:10.1007/978-3-319-28624-2_16

Conflict of Interest: The author declares that the research was conducted in the absence of any commercial or financial relationships that could be construed as a potential conflict of interest.

Copyright (C) 2021 Nandy. This is an open-access article distributed under the terms of the Creative Commons Attribution License (CC BY). The use, distribution or reproduction in other forums is permitted, provided the original author(s) and the copyright owner(s) are credited and that the original publication in this journal is cited, in accordance with accepted academic practice. No use, distribution or reproduction is permitted which does not comply with these terms. 